\title{
Prevalence of Conventional Risk Factors in ST Segment Elevation Myocardial Infarction Patients in Shahid Gangalal National Heart Centre, Nepal
}

\author{
Chandra Mani Adhikari,' Dipanker Prajapati, ${ }^{1}$ Bibek Baniya, ${ }^{1}$ Sudhir Regmi, ${ }^{1}$ Amrit Bogati, ${ }^{1}$ Suman Thapaliya' \\ 'Department of Cardiology, Shahid Gangalal National Heart Centre, Bansbari, Kathmandu, Nepal.
}

Introduction: Smoking, diabetes mellitus, hypertension, and dyslipidemia are labelled as conventional risk factors for coronary artery disease. Prevalence of these risk factors varies across populations. This study aimed to assess the prevalence of these conventional risk factors in patients, who were discharged from our hospital, with the diagnosis of ST elevation myocardial infarction.

Methods: Medical records of 495 ST elevation myocardial infarction patients discharged from our centre in between January 2012 to December 2012 were retrospectively reviewed to evaluate the prevalence of conventional risk factors.

Results: Clear dominance (75\%) of male patients was seen. Inferior wall myocardial infarction $(29.9 \%)$ was the most common diagnosis followed by anterior wall myocardial infarction $(25.1 \%)$. Hypertension (65\%), smoking (57.8\%) and dyslipidemia (45.5\%) were the most common risk factors. Diabetes $(31.1 \%)$ was the least common. Prevalence of hypertension, dyslipidemia was similar among male and female. Smoking was statistically common in male (76.8\%vs $49.5 \%)$,though diabetes was common in female (36.5\%vs.29.3\%) not statistically significant.

Conclusions: Conventional risk factors are common among ST elevation myocardial infarction patients. Early detection and treatment of these risk factors play a vital role for the prevention of coronary artery disease. Much more focus should be stressed on preventive programs throughout the country.

Keywords: coronary artery disease; diabetes; dyslipidemia; hypertension; smoking; ST elevation myocardial infarction.

\section{INTRODUCTION}

Coronary artery disease (CAD) is a leading cause of morbidity and mortality in both developing and developed countries. ${ }^{1}$ Among the different forms of coronary artery disease, ST elevation myocardial infarction (STEMI) has the highest in-hospital mortality. ${ }^{2}$

Correspondence: Dr. Chandra Mani Adhikari, Shahid Gangalal National Heart Centre, Bansbari, Kathmandu, Nepal. Email: topihap@mail.com, Phone: +977-9851212111. 
Adhikari et al. Prevalence of conventional risk factors in ST segment elevation myocardial infarction patients in Shahid Gangalal ...

Epidemiological studies have established cigarette smoking, ${ }^{3}$ diabetes mellitus (DM) ${ }^{4}$ hypertension (HTN), ${ }^{5}$ and dyslipidemia ${ }^{6}$ as independent risk factors for CAD and have been labeled as conventional risk factors. ${ }^{7}$ Treatment of these risk factors has been convincingly shown to reduce the risk of future events. ${ }^{3,8}$ Prevalence of these risk factors may vary across populations. ${ }^{9,10}$ This study aimed to assess the prevalence of conventional risk factors in patients who were discharged from our hospital after treatment of STEMI.

\section{METHODS}

It is a retrospective, single centre study, performed at Shahid Gangalal National Heart Centre, Bansbari, Kathmandu, Nepal. Medical records of 495 acute STEMI patients who were admitted for the first time and were discharged in between January 2012 to December 2012 were retrospectively reviewed. Performa was designed to collect patient information which included; age, gender, diabetes, dyslipidemia hypertension, smoking, left ventricular function, reperfusion strategies were recorded.

Cardiovascular risk factors were defined according to American College of Cardiology Key Data Elements and Definitions for Measuring the Clinical Management and Outcomes of Patients with Acute Coronary Syndrome.

1. Smoking: History confirming cigarette smoking (regularly smokes one or more cigarettes per day)

2. Dyslipidemia: History of Dyslipidemia diagnosed and/or treated by physician or meets the criteria of National Cholesterol Education Program:

a. Total cholesterol (TC) greater than $5.18 \mathrm{mmol} / \mathrm{l}$; or

b. Low-density lipoprotein (LDL) greater than or equal to $3.37 \mathrm{mmol} / \mathrm{L}$; or

c. High-density lipoprotein (HDL) less than $1.04 \mathrm{mmol} / \mathrm{L}$.

3. Hypertension (HTN): defined as blood pressure $\geq$ $140 / 90 \mathrm{mmHg}$ or on treatment.

4. Diabetes (DM): defined as a fasting glucose $\geq 7.1$ $\mathrm{mmol} / \mathrm{L}$ or on treatment.

5. Impaired Fasting Glucose (IFG): defined as fasti glucose more than $5.4 \mathrm{mmol} / \mathrm{l}$.
All the variables were entered into the Statistical Package for Social Sciences software, version 14 (SPSS Inc) for data analysis. Descriptive statistics were computed and presented as mean and standard deviation for continuous variables like age and Left Ventricular Ejection Fraction (LVEF), categorical variables were reported in percentages for the gender, hypertension, diabetes mellitus, dyslipidemia.

\section{RESULTS}

A total of 495 patients who were discharged with the diagnosis of STEMI were included in this study. Table-1 shows the demographic and clinical characteristics of the studied cohort. The mean age was $56.9 \pm 12.4$ years. Of the total number of patients included in the study, $372(75.1 \%)$ were male and 123 (24.9\%) were female.

Table 1. Demographic and clinical characteristics.

\begin{tabular}{lcc|}
\hline Demographic and clinical character $\quad \mathrm{n}=495$ (\%) \\
Mean Age & $56.9+12.4$ years \\
Total cholesterol & $4.2 \pm 0.9 \mathrm{mmol} / \mathrm{L}$ \\
$\mathrm{HDL}$ & $1.0 \pm 0.1 \mathrm{mmol} / \mathrm{L}$ \\
LDL & $2.3 \pm 0.8 \mathrm{mmol} / \mathrm{L}$ \\
Fasting Blood Sugar & $6.7 \pm 2.9 \mathrm{mmol} / \mathrm{L}$ \\
LVEF & $45.9 \pm 12.7 \%$ \\
Male & 372 & $(75.1)$ \\
Female & 123 & $(24.9)$ \\
Streptokinase & 53 & $(10.7)$ \\
Primary Percutaneous coronary & \\
intervention & 79 & $(15.9)$ \\
LVEF < 40\% & 171 & (34.5) \\
LVEF $>40 \%$ & 324 & (65.5)
\end{tabular}

As shown in table 2 Inferior wall Myocardial infarction(MI) was the most common among the discharged patient followed by Anterior wall MI, Extensive anterior wall $\mathrm{MI}$, Inferior posterior $\mathrm{MI}$ and anteroseptal wall $\mathrm{MI}$ respectively. 
Adhikari et al. Prevalence of conventional risk factors in ST segment elevation myocardial infarction patients in Shahid Gangalal ...

\begin{tabular}{|lll|}
\hline \multicolumn{3}{l}{ Table 2. Myocardial infarction distribution. } \\
\hline & $\mathrm{n}$ & $\%$ \\
Inferior & 148 & 29.9 \\
Anterior & 124 & 25.1 \\
Extensive Anterior wall & 70 & 14.1 \\
Inferior-posterior & 45 & 9.1 \\
Antero septal & 43 & 8.7 \\
Infero lateral & 13 & 2.6 \\
Inferior RV & 13 & 2.6 \\
Inferior posterior lateral & 10 & 2.0 \\
Lateral & 8 & 1.6 \\
Antero lateral & 6 & 1.2 \\
Antero inferior & 5 & 1.0 \\
Inferior-posterior RV & 4 & 0.8 \\
Posterior lateral & 3 & 0.6 \\
posterior & 2 & 0.4 \\
LBBB & 1 & 0.2 \\
\hline
\end{tabular}

smoking, dyslipidemia and DM. Table 4 clearly showed that smoking was significantly more among male compared to female. Though DM was more common in female compared to male it was not statistically significant. Other two risk factors HTN and dyslipidemia were equally present among male and female.

As shown in table 5, STEMI patients without any conventional risk factors were negligible. In more than $70 \%$ patient two or more risk factors were present.

\begin{tabular}{|lll|}
\hline \multicolumn{3}{|l|}{ Table 5. Distribution of risk factors burden. } \\
\hline Risk factors & $\mathrm{n}$ & $\%$ \\
None & 15 & 3.1 \\
One & 130 & 26.3 \\
Two & 210 & 42.4 \\
Three & 122 & 24.6 \\
Four & 18 & 3.6 \\
\hline
\end{tabular}

Of the patients studied, the most patients fall under the age group of more than 65 years and the least was of age group less than 35 years old. Male patients in age group of 35-44 years were significantly more than female.

\begin{tabular}{|c|c|c|c|c|}
\hline & Total (\%) & $\begin{array}{l}\text { Male n } \\
(\%)\end{array}$ & Female & $\begin{array}{l}\mathrm{P} \\
\text { value }\end{array}$ \\
\hline$<35$ & $7 \quad(1.5)$ & $5(1.3)$ & $2(1.6)$ & 0.81 \\
\hline $35-44$ & $55(11.1)$ & $49(13.2)$ & $6(4.9)$ & 0.01 \\
\hline $45-54$ & $114(23.0)$ & $83(22.3)$ & $31(25.2)$ & 0.50 \\
\hline $55-64$ & $148(29.9)$ & $111(29.8)$ & $37(30.1)$ & 0.95 \\
\hline$>65$ & $171(34.5)$ & $124(33.4)$ & $47(38.2)$ & 0.32 \\
\hline
\end{tabular}

Table 4. Distribution of Risk factor among male and female.

\begin{tabular}{|c|c|c|c|c|}
\hline & Over all & $\begin{array}{l}\text { Male } \\
(\%)\end{array}$ & Female & $P$ value \\
\hline HTN & $\begin{array}{l}324 \\
(65.4)\end{array}$ & $\begin{array}{l}242 \\
(65.3)\end{array}$ & $82(66.6)$ & 0.74 \\
\hline DM & $\begin{array}{l}154 \\
(31.1)\end{array}$ & $\begin{array}{l}109 \\
(29.3)\end{array}$ & $\begin{array}{l}45 \\
(36.5)\end{array}$ & 0.13 \\
\hline $\begin{array}{l}\text { Dyslip } \\
\text { idemia }\end{array}$ & $\begin{array}{l}225 \\
(45.5)\end{array}$ & $\begin{array}{l}173 \\
(46.8)\end{array}$ & $\begin{array}{l}52 \\
(42.3)\end{array}$ & 0.41 \\
\hline Smoking & $\begin{array}{l}286 \\
(57.8)\end{array}$ & $\begin{array}{l}285 \\
(76.8)\end{array}$ & $\begin{array}{l}61 \\
(49.5)\end{array}$ & 0.001 \\
\hline
\end{tabular}

HTN was the most common risk factor followed by

\section{DISCUSSION}

Risk factor is a trait that predicts the risk of developing a clinically significant disease within a certain population at risk. The Framingham Heart Study played a pivotal role in defining the risk factors involved in the pathogenesis of CAD. It also helped the health care professionals to focus their attention on at high risk population and implement the strategies both for the primary and secondary prevention. ${ }^{11}$ In Western populations, major conventional risk factors, such as HTN, dyslipidimea, cigarette smoking, DM, obesity, and physical inactivity, predict much of the individual, as well as general population, risk of CAD..$^{2,13,14}$

Our data concerning higher prevalence of $\mathrm{Ml}$ and male sex predominance in ACS patients is consistent with report from multinational observational Global Registry of Acute Coronary Events (GRACE). ${ }^{15}$

Our study clearly demonstrates that in STEMI patients HTN (65\%), smoking (57.8\%) and dyslipidemia(45.5\%) are the most frequent risk factors. DM (31\%) was least common risk factor in our patient population. In STEMI patient who underwent Primary $\mathrm{PCl}$ the prevelance of these risk factors were Dyslipidimea(61\%), Smoker(60\%),HTN(51\%)and DM(30\%).16Though the prevelance of somking and DM was quite similar, HTN is significantly more in our study whereas Dyslipidimea was lesser than previous study. There was not much difference in prevalence of dyslipidimea and HTN among male and female however there is a significant difference was noted in the prevalence of smoking and DM. Our study clearly showed that Smoking is more 
common in male compared to female where as DM is more common in female than Male.

DM is now a major public health challenge in many Asian populations. Though its prevalence is somewhat lower than those observed in developed countries, ${ }^{17}$ it is significantly more common among South Asians, having $2 \%$ prevalence in rural South Asia but approaching 20\% prevalence in urban South Asia and amongst immigrant South Asians. ${ }^{18,19,20}$ In our study it is least common among the conventional risk factors. A study on risk factors in CAD patients in Kerala21 showed Diabetes mellitus was found to be a major risk factor in both males and females in the study population. $58 \%$ had diabetes mellitus, and $21 \%$ were with impaired glucose tolerance. Of the male patients, $54 \%$ were diabetics and $20 \%$ were found with impaired glucose tolerance. For the female group, the values were $54 \%$ and $20 \%$, respectively. Prevalence of DM in INTERHEART study was $26 \%$ in women, $16 \%$ in men. ${ }^{22}$ In a study in which cardiovascular risk factors were analyzed in Turkish patients with coronary angiographically documented CAD, prevalence of DM was detected in a higher percentage in women than in men $(31 \%$ versus $18 \%$, respectively). ${ }^{23}$ Consistent with these studies, DM was observed to have higher prevalence in women than in men $(38 \%$ versus $16 \%)$ in our study. A low incidence of hypertension (39\%) was seen among the study population in CAD patients of Kerala. ${ }^{21}$ In Sofia Study and EUROSPIRE study, hypertension has been seen as a major risk factor for CAD. ${ }^{24}$

Hypertension is the most common conventional risk factor in our study. It was reported in INTERHEART study that prevalence of HTN in male patients with acute myocardial infarction was $35 \%$, while it was $53 \%$ in females. ${ }^{22}$ It was also reported in the same study that HTN and DM were the strongest risk factors for acute myocardial infarction after smoking. ${ }^{22}$ A study in patients with CAD in Turkey found that prevalence of HTN was $37 \%$ in men and $60 \%$ in women. ${ }^{23}$ In our study, prevalence of HTN was most common over all with no difference in the prevalence between male and female.

Cigarette smoking and/or use of other tobacco products is one of the most important, avoidable risk factors of ACS among men and women. It is a serious public health problem around the world, was the second most frequently encountered conventional risk factor with acute STEMI living in Turkish study population. ${ }^{25}$ Tobacco use was present in $68 \%$ of all the subjects. In our study it was the second most common conventional risk factor overall where as it was the most common risk factor among males. Our study showed that almost $50 \%$ of the females are tobacco consumers. In a study done in CAD patients of Kerala $76 \%$ had never smoked in their lifetime, and only $8 \%$ were current smokers. The number of females who smoked in the study population was $0 \%$. In INTERHEART study, it was reported that smoking was one of the most powerful risk factor on population attributable risk and it was associated with a three-fold increase in odds of a nonfatal acute myocardial infarction, compared with those who never smoked. ${ }^{22}$ It was suggested that most of the acute myocardial infarction cases could be prevented by smoking cessation only.

The importance of dyslipidemia in the pathogenesis of CAD is well-known. ${ }^{26}$ In our study dyslipidemia was present is $45 \%$ patient. There is no significant difference in Male and female in the prevalence of dyslipidimea.

Our study clearly showed that the conventional risk factors occur in cluster. In a study ${ }^{27}$ on risk factors among young ACS patient more than $85 \%$ patient had more than two risk factors whereas our study showed more than $70 \%$ patient had more than two risk factors.

The true prevalence of the conventional risk factors is certainly higher than the identified in our study. As approximately $32 \%$ of patients with hypertension are unaware that they are hypertensive. ${ }^{28}$ Higher rates of unawareness have been documented for dyslipidimea and diabetes. ${ }^{29,30}$ In addition physicians typically underdiagnosed conventional risk factors. ${ }^{31}$

There are several limitations of our study. It is a single centre, retrospective study without a control group. Our study also has the survival bias $^{7}$ as patients included in our study were survival of the STEMI.As we know studies ${ }^{32,33}$ in the past few decades have shown that acute $\mathrm{MI}$ results in a significant decrease in the serum levels of total cholesterol, LDL cholesterol, and HDL cholesterol it may decrease the prevalence of dyslipidemia.

\section{CONCLUSIONS}

Conventional risk factors are common among STEMI patients. Early detection and treatment of these risk factors play a vital role for the prevention of CAD. We should focus on preventive programs throughout the country. 
Adhikari et al. Prevalence of conventional risk factors in ST segment elevation myocardial infarction patients in Shahid Gangalal ...

\section{REFERENCES}

1. Lopez AD, Murray CC. The global burden of disease, 1990-2020. Nat Med 1998;4:1241-3.

2. Nazif Aygül, Kurtulufl Özdemir, Adnan Abac et al.Risk factors of myocardial infarction in Central Anatolia.Anadolu Kardiyol Derg 2009; 9: 3-8.

3. The Health Benefits of smoking cessation:A report of the surgeon general.Rockville,Md:US Dept of Health and Human Services;1990. DHHS publication (CDC) 90-8416.

4. Stamler J,Vaccaro O,Neaton JD,Wentworth D. Diabetes, other risk factors, and 12-yr cardiovascular mortality for men screened in the multiple risk factor intervention trail. Diabetes care.1993;16:434-444.

5. MacMahon S,Peto R,Cutler J et al.Blood pressure, stroke, and coronary heart disease, I:prolonged differences in blood pressure:prospective observational syudies corrected for the regression dilution bias.Lancet. 1990;335:765-774.

6. Verschuren WM,Jacobs DR,Bloemberg BP,et al.Serum total cholesterol and long-term coronary heart disease mortality in different cultures:twenty-five year follow-up of the seven countries study.JAMA. 1995;274:131-136.

7. Khot U,Khot M,Bajzer C,Sapp S,Ohman E,Brener S,Ellis S,Lincoff A,Topol E. Prevelance of conventional risk factors in patients with coronary heart disease.JAMA.2003;290:898-904.

8. Collins R,Peto R,MacMahon S,et al.Blood pressure stroke, and coronary heart disease,II:short term reductions in blood pressure:overview of randomized drug trails in their epidemiological context.Lancet. 1990;335:827-838.

9. Yusuf S, Hawken S, Ounpuu S, Dans T, Avezum A, Lanas F, et al;INTERHEART Study Investigators. Effect of potentially modifiable risk factors associated with myocardial infarction in 52 countries (the INTERHEART study): case-control study. Lancet 2004; 364: 937-52.

10. Onat A, Uzunlar B, Hergenc G, Yaz`c $>$ M, Uyarel H, Toprak $S$, et al. Distribution of Risk Variables and Global Risk Across Geographic Regions of Turkey. Turk Kardiyol Dern Arfl 2003; 31: 323-30.

11. Muhammad Asif Bhalli,Azhar Mehmood Kayani,Naseer Ahmed Samore.Frequency of risk factors in male patients with Acute Coronary Syndrome. Journal of the college of Physicians and Surgeons Pakistan. 2011,Vol 21 (5):271-275.

12. Magnus $\mathrm{P}$, Beaglehole R. The real contribution of the major risk factors to the coronary epidemics. Time to end the "only-50\%"myth. Arch Intern Med. 2001;161:2657-2660.

13. Stamler J, Stamler R, Neaton JD, et al. Low risk-factor profile and long-term cardiovascular and noncardiovascular mortality and life expectancy: findings for 5 large cohorts of young adult and middle-aged men and women.JAMA. 1999;282:2012-2018.

14. D'Agostino RB Sr, Grundy S, Sullivan LM,Wilson P. HD Risk Prediction Group. Validation of the Framingham coronary heart disease prediction scores: results of a multiple ethnic groups investigation. JAMA. 2001;286:180-187.

15. Carruthers KF, Dabbous OH, Flather MD, et al. Contemporary management of acute coronary syndromes: does the practice match the evidence? The global registry of acute coronary events (GRACE). Heart 2005; 91: 290-8).

16. Adhikari CM, Bhatta YD, Malla R, et al. Outcomes of Primary Percutaneous Coronary Intervention at Shahid Gangalal National Heart Centre, Kathmandu, Nepal. Journal of Advances in Internal Medicine 2013;02(01):6-9.

17. King H, Aubert RE, Herman WH. Global burden of diabetes, 1995-2025: prevalence,numerical estimates, and projections. Diabetes Care. 1998;21:1314-1331.

18. Anand SS, Yusuf S, Vuksan V, Devanesen S, Teo KK, Montague PA, Kelemen L, Yi C, Lonn E, Gerstein H, Hegele RA, McQueen M. Difference in risk factors, atherosclerosis, and cardiovascular disease between ethnic groups in Canada: the Study of Health Assessment and Risk in Ethnic groups (SHARE). Lancet. 2000; 356: 279-284.

19. Riste L, Farida Khan F, Cruickshank J. High diabetes prevalence in all ethnic groups including Europeans in a British inner city: poverty, history, inactivity or 21st century Europe? Diabetes Care 2001; 24: 1377-1383.

20. Venkataraman R, Nanda NC, Baweja G, Parikh N, Bhatia V. Prevalence of diabetes mellitus and related conditions in Asian Indians living in the United States. Am J Cardiol. 2004; 94: 977-980.

21. Cyril James. Risk Factors for Coronary Artery Diseases: A Study Among Patients With Ischemic Heart Disease in Kerala. Heart India,2013; 1:7-11.

22. Yusuf S, Hawken S, Ounpuu S, Dans T, Avezum A, Lanas F, et al;INTERHEART Study Investigators. Effect of potentially modifiable risk factors associated with myocardial infarction in 52 countries (the INTERHEART study): case-control study. Lancet 2004; 364: 937-52.

23. Sonmez K, Akcay A, Gencbay M, Akcakoyun M, Demir D, Elonu $\mathrm{OH}$,et al. Prevalence of risk factors in patients with angiographically demonstrated coronary artery disease. Turk Kardiyol Dern Ars 2002; 30: 191-8.

24. Euroaspire III: lifestyle, risk factor and therapeutic management in people at high risk of developing cardiovascular disease from 12 European regions. Heart 2009;95:4.

25. Nazif Aygül, Kurtulufl Özdemir, Adnan Abac, Meryem Ülkü Aygül, Mehmet Akif Düzenli, Mehmet Akif Vatankulu,et al. Prevalence of risk factors of ST segment elevation myocardial infarction in Turkish patients living in Central Anatolia. Anadolu Kardiyol Derg 2009; 9: 3-8.

26. Mohan V, Sandeep S, Deepa R, Shah B, Varghese C. Epidemiology of type 2 diabetes: Indian scenario. Indian J Med Res 2007;125:217-30.

27. Adhikari CM, Rajbhandari R,Limbu YR, Malla R, Sharma $\mathrm{R}$, Rauniyar B et al. A study on major cardiovascular risk factors in Acute Coronary Syndrome (ACS) patient 40 years and below admitted in CCU of Shahid Gangalal National Heart Center. Nepalses heart Journal.2010;7(1):20-24.

28. Hyman DJ,Pavlik VN.Characteristics of patients with uncontrolled hypertension in United States.N Eng J Med.2001;345:479-486. 
29. Nieto FJ,Alonoso J, Chambless LE, etal. Population awareness and control of hypertension and hypercholesterolemia;the Atherosclerosis Risk in Communities Study. Arch Intern Med. 1995;155:677-684.

30. Franse LV, Di Bari M, Shorr RI, et al. Type 2 diabetes in older well functioning people:who is undiagnosed?data from the Health,Aging, and Body Composition Study.Diabetes Care. 2001;24:2065-2070.
31. Hyman DJ, Pavlik VN. Self-reported hypertension treatment practices among primary care physicians:blood pressure thresholds, drug choice, and the role of guidelines and evidence based medicine. Arch Intern Med. 2000;160:2281-2286.

32. Watson WC, Buchanon KD, Dickon C. Serum cholesterol levels after myocardial infarction. Br J Med 1963; 2:709-712.

33. Pyfe T, Baxter RH, Cochran DM, et al. Plasma lipid changes after myocardial infarction. Lancet 1971; 2:997-1001. 